\title{
Managed Play: The Media's Impact on Play in the Australian Football League
}
Authors' contribution:
A) conception and design of the study
B) acquisition of data
C) analysis and interpretation of data
D) manuscript preparation
E) obtaining funding

\author{
Samuel Keith Duncan \\ Holmesglen Institute, Australia, Victoria
}

ABSTRACT

No industry has influenced the transformation of the Australian Football League (AFL) into a professional, commercial business more than the media. Today, the AFL players are paid more than ever and are used as marketing tools to promote and sell the game, often to new fans in new markets of Australia - namely New South Wales and Queensland - who haven't traditionally played Australian Football, preferring the rugby codes instead.

But perhaps the biggest change in the AFL is that the play element is now used as function of business. Put simply, winning leads to more money. As such, the play element is now manipulated more than ever. The game has more coaches implementing more tactics, strategies, game plans and set plays than ever before. These changes can be linked back to the media's influence on the game.

This paper utilises the combined observations and theories of Johan Huizinga and Pierre Bourdieu to create a theoretical lens through which we can understand the media's growing influence in sport and its impact on play's transformation. The theory will then be expounded through an extensive analysis of the media's influence in the AFL, particularly its play element. This analysis will be supported with insights and views from AFL fans, members, commentators and theorists.

play, media, sport, Huizinga, Bourdieu

\section{Introduction}

Perhaps no form of sport has created, shaped, and bound Australian communities and culture together quite like Australian football. Created in Australia by Australians, the original game reflected the characteristics of the Australian people as its motto, "the people's game", suggests (Orive 1996, p 52). We played the game with a spirit, passion, enthusiasm, and vibrancy that reflected our ownership of the game and the pride we felt in representing our respective teams and communities.

Today, we have restricted sport - and Australian football in particular - through structure, analysis, and a desire to win. We review each individual and team performance, analysing it and judging it as a business does. We measure its efficiency and effectiveness through a range of modern-day statistics such as contested possessions, hardball gets, loose ball gets, inside 50s, and clearances. What once was a game has become a business and, as such, must be careful with its image. Thus, our relationship with play in the Australian Football League (AFL) is increasingly determined by how the league and the media package play and how we consume the AFL brand and engage with it.

This paper seeks to understand this transformation of play by combining Johan Huizinga's historical observations of play with Pierre Bourdieu's concepts of field and capital. Through this theory we can 
understand the reasons behind play's transformation and highlight the role of the media field in play becoming a function of business.

Bourdieu's theories and concepts have been utilised extensively in the broader study of sport ${ }^{1}$. However, he has not previously been utilised as a means of understanding the corruption of play, much less the corruption of play in the Australian Football League. Likewise, many play theorists, such as Caillois, Hans, Millar and Sutton-Smith ${ }^{2}$ have studied the evolution of play and the transformation of games to sport. Within these studies, various consequences of the commercialisation of sport have been expounded.

However, this study discusses the corruption of play at the hands of the commercialisation of sport and, through the theories and concepts of Bourdieu, provides a means by which we can understand how and why play has been corrupted. By doing so, a means of understanding how things could be different, or changed, is developed. Indeed, the theoretical framework used to analyse play's corruption in the AFL can be applied to many fields of society. This makes this paper an important contribution to the broadly understood study of play.

Furthermore, by exploring the AFL as a case study, we are able to illuminate the importance of play, and in particular, winning, from a business and commercial perspective. This analysis further highlights how and why the play element has been transformed by the media field. The theory and analysis of the AFL is enriched by the views of various AFL and club members who have observed the increasing role of the media in the league and the subsequent transformation of play.

\section{The Commodification and Corruption of Play}

Play: "activity engaged in for enjoyment and recreation"; the act of "engag[ing] in activity for enjoyment and recreation rather than [for] a serious or practical purpose" (Oxford English Dictionary 2017). In his most famous study of play, Homo Ludens: A Study of the Play Element in Culture, Dutch historian Johan Huizinga describes play as "a discharge of superabundant vital energy" to seek the satisfaction of imitative instinct (Huizinga 1950, p. 2).

Four characteristics define play for Huizinga (1950, p, 8):

1. Play is free, in fact, it is freedom,

2. Play is not ordinary or real,

3. Play is secluded and limited,

4. Play "creates order, is order".

He goes on to define the play element as:

A free activity standing quite consciously outside ordinary life, as being "not serious" but at the same time absorbing the player intensely and utterly. It is an activity connected with no material interest and no profit can be gained from it. It proceeds within its own proper boundaries of time and space and according to fixed rules and in an orderly manner. It encourages the formation of social groupings, which tend to surround themselves with secrecy and to stress their difference from the common world by disguise or other means (Huizinga 1950, p. 13).

For Huizinga, the notions of fun, enjoyment, and freedom underpin the key characteristics of play (Huizinga 1950, p. 2): Play must be fun, free and voluntary, spontaneous, and separate from the ordinary and real. In its most autonomous sense, play creates, encourages, and stimulates meaningful

\footnotetext{
${ }^{1}$ For a more detailed overview of how Bourdieu has been utilised in sports studies see: Tomlinson, A. (2004). Pierre Bourdieu and the Sociological Study of Sport: Habitus, Capital and Field. In R. Guilianotti (Ed.), Sport and Modern Social Theorists. Basingstoke: Palgrave Macmillan.

${ }^{2}$ For a more in depth analysis of play theorists and their critique of Huizinga see: Caillois, R. (2006). The Definition of Play and The Classification of Games. In K. Salen, and E. Zimmerman (Eds.), The Game Design Reader: A Rules of Play Anthology, Massachusetts. Boston: Institute of Technology; Sutton-Smith, B. (1997) The ambiguity of play. Cambridge: Harvard University Press; Hans, J.S. (1981). The play of the world. Boston: University of Massachusetts Press; Duncan, S. (2016). Footy Grounds to Grandstands: Play, Community and the Australian Football League. Port Adelaide: Ginninderra Press.
} 
relationships. While play can be serious when engaged in the "play contest", when players are no longer having fun or enjoying themselves while playing or no longer feel free when doing so, they have ceased to play. Importantly for Huizinga, play should be free, with participants engaging in it voluntarily. They should not have to pay to play, nor should they receive financial reward for playing. When play participants are no longer free and if they are paid to play, the play element has been corrupted.

The notion of the play element losing its freedom is best understood by analysing its influence beyond the sporting field. For Huizinga, play, at its purest, is separate from the ordinary and real. That is, the significance of the play contest is minimal once the play contest is over. No matter how intense, passionate or serious the play contest is, its importance in real life is minimal. As Huizinga notes (1950, p. 49), "The contest is largely devoid of purpose - that the action begins and ends in itself and the outcome does not contribute to necessary life processes of the group." Fundamental to this characteristic of play is that the players are acting autonomously from the roles, responsibilities and power they may have in other aspects of their lives. Furthermore, for Huizinga, play is inferior to real life. Players are "only playing" and the consequences beyond the contest are not significant. Huizinga states that when play loses its autonomy, when the significance of play stretches beyond the conclusion of the contest and empowers participants beyond the play field, then it is no longer "play"; it is "false play" (Huizinga 1950, p. 206).

Huizinga identifies the corruption of play with increasing structure, control and restriction with an obsessive emphasis on winning or "being the best." These characteristics have flourished at the expense of freedom, creativity, spontaneity and flair. The Dutch researcher believes that over the course of the centuries we have transformed play from its free, creative self, first, into sport and, ultimately, into business. He (1950, p. 74) traced the origins of this transformation to the Roman Empire - the Romans found they could organize play and use it as a tool to entertain thousands of spectators who packed stadiums such as the Colosseum.

The notion of organised sport as we know it today, a recognizable and structured organisation, is a far more recent phenomenon, emerging in Britain during early industrialization (Rowe 2004, p. 11). According to Huizinga (1950, p. 13) the ruling class used play to distract the proletariat from their subordinated and "dull existence." In doing so they transformed play from a spontaneous activity, adopting a more organised structured model. Huizinga (1950, p. 196) noted that play was transformed from an item of "occasional amusement to a system of organised clubs and matches." Play, in this instance has been influenced by market forces - it was now a tool, used as a secondary purpose - to distract the masses, provide workers with an escape and ensure they remained fit and healthy. Huizinga (1950, p. 206) described this kind of play as the aforementioned "false play" - he claimed that "civilisation today is no longer played and even where it seems to be play, it is false play."

Christopher Lasch (1980) supported this notion in The Culture of Narcissism: American Life in an Age of Diminishing Expectations. He claimed that all types of leisure time and play forms have been corrupted by money and the necessary calculations, prudence, analysis and efficiency that defines the business world. As with most business functions, play is restricted by structure, analysis and a desire to succeed or not to fail (Lasch 1980, p. 74).

Thus, play lost its autonomy and became a commodity, the crowds becoming its consumers. Influenced by economics and, more specifically money, it lost its carefree, spontaneous, creative nature and became more and more organised and structured throughout the twentieth century and into the twenty-first. As this commodification continued, play also became more serious.

\section{Understanding Huizinga's Observations through the Concepts of Pierre Bourdieu}

While Huizinga's historical observations are insightful and largely accepted as the classical study of play, many other theorists such as Millar (1968), Hans (1981) Sutton-Smith (1997) and Caillois (2006), have made significant contributions to the study of play. Furthermore, one of the criticisms levelled at Huizinga by those who have contributed to the field, is that his observations, while insightful, lack theoretical rigour, or a conceptual framework, that would enable his observations to be applied to understand the transformation of modern professional play, or indeed other fields of society. However, by applying Pierre Bourdieu's concepts of fields, capital and habitus to Huizinga's observations, a theoretical framework can be developed to 
conceptualise what has happened to play and how play's transformation can be observed in practice, using a case study of today's modern sports. Furthermore, adopting Bourdieu's concepts of field and capital in the language we use to illuminate play's transformation can help understand the changing characteristics of play and reasons for what Huizinga described as "the corruption of play."

Bourdieu develops his concepts as a means of understanding how citizens relate to each other. His theory of field concerns the reasons people behave as they do at certain times and in certain environments (Bourdieu 1979, p. 69). His notions of capital and habitus concern how citizens within the same field seek to gain power from each other within the limitations of that field. He concludes that the behaviour of citizens and the relationships they share with each other reflect their environment and simply serve to legitimise and reinforce the existing structure of their surroundings (Bourdieu 1986, p. 249).

Bourdieu (1986, p. 249) argues that what appear to be autonomous individuals acting according to their own interests are actually products of an emergent historical system of social relations that constrain them to recognise each other and compete with each other for socially recognised forms of power or capital. Capital is any form of power that allows actors to participate in a given field of society to gain further capital, thereby augmenting their positions in the field.

Bourdieu identifies four types of capital: social capital, cultural capital, symbolic capital, and economic capital. Social capital consists of resources based on group membership, relationships, and networks or influence and support. It is "the aggregate of the actual or potential resources which are linked to possession of a durable network of more or less institutionalised relationships of mutual acquaintance and recognition" (Bourdieu 1986, p. 249). Cultural capital consists of nonfinancial social assets that promote social mobility beyond economic means, including the forms of knowledge, skills, education, and advantages people have that give them higher status in society. Parents provide their children with cultural capital by transmitting the attitudes and knowledge needed to succeed in the current educational system. Symbolic capital refers to the resources available to individuals on the basis of honour, prestige, or recognition. Economic capital is one's command over economic resources (e.g., cash and financial assets) (Bourdieu 1986, pp. 249-250).

For Bourdieu, the modern social world is broken into various fields. A field is any structure of social relations in which citizens compete for capital and, in doing so, struggle against each other to establish their positions within that space. Among the main fields in modern society, Bourdieu cites the arts, education, law, politics, and the economy (Bourdieu 1990, p. 51). Particularly important is Bourdieu's belief that the different actors within each field tend to strive for capital specific to that field independent of the capital in any other field. Thus, each field of society is autonomous and independent of the influences and characteristics of other fields. However, Bourdieu also holds that because the economic field is the most dominant, powerful, and increasingly influential field, maintaining the autonomy of other fields is essential to limiting the power of those with economic capital (Bourdieu 1986, p. 258). When fields lost their autonomy, the participants within the field begin striving for capital from the most dominant field. Thus, when the sport field mergers with the economic field it is likely that players will no longer simply be satisfied accumulating social, cultural and symbolic capital specific to the field, they will also compete for economic capital (money), which will give them power in other fields beyond the sport field.

In reviewing Huizinga's historical observations, it's clear that his view was that when a field loses its autonomy to other fields of society, play loses its authenticity and the key characteristics of play, based on fun, enjoyment, spontaneity and creativity are undermined by the most important characteristics of the field that merges with sport. One of the most dominant fields to merge with sport at the professional level is the media field, which has transformed sport into a business and, in doing so, transformed the key characteristics that now define professional play. 
This can be understood through the below image:

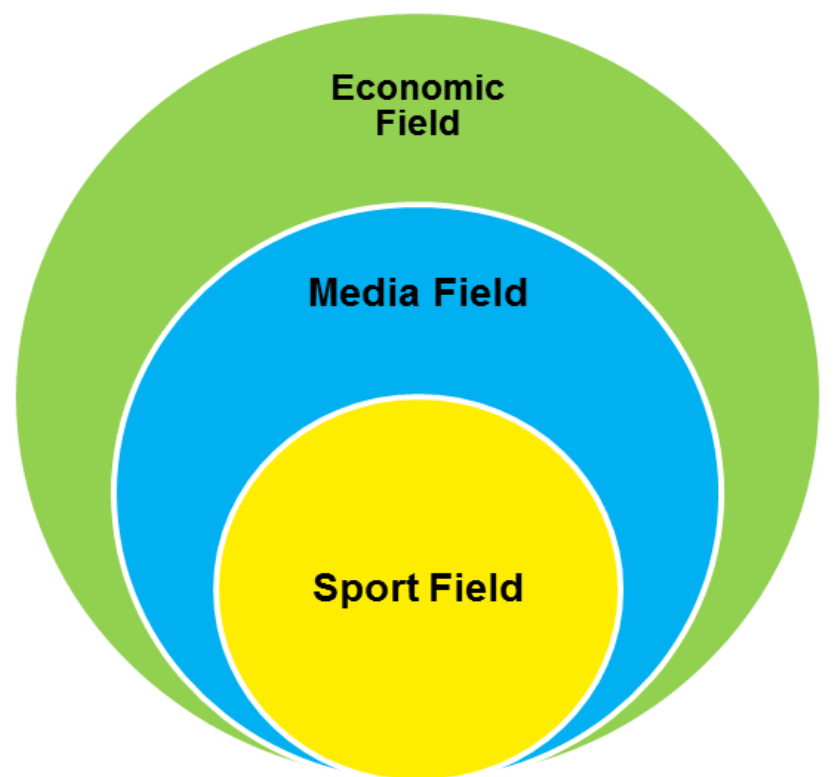

Figure 1: The sport field, media field and economic field today

Source: Own study.

The merger of the media field with the sport field means that sport is now an entertainment business that sits within the broader economic field, meaning that accumulating economic capital (money) is one of the primary objectives of those participating within the sports field at the professional level (leagues, clubs, sponsors, players, coaches). The accumulation of economic capital within the sport field will also give participants power in other fields, meaning the sport field, and play, is no longer autonomous and no longer separate from the ordinary or real.

Because play is largely the purpose of the sport field, it is the primary means by which the participants within the field can accumulate economic capital. Playing well, indeed winning, leads to a range of commercially advantageous outcomes - higher gate receipts from crowd attendances, more members, richer sponsorship deals - which ensures the success, or even survival of the club. Thus, play is carefully managed, analysed and scrutinised as a business function. Clubs are now businesses. Players are now employees of clubs. Coaches are managers. Consequently, play is no longer spontaneous, creative and free.

The study of the media's influence on sport is a growing one, with scholars such as Lawrence and Rowe (1986), Whannel (2000), Rowe (2004) and Nicholson, Kerr and Sherwood (2015) providing significant contributions to the impact of the media in commercialising and professionalising sport and in examining the sports-media nexus. However, the analysis of the media's impact on the play element in professional sport has been less thoroughly explored and the idea of understanding the transformation of play through the observations and theories of Huizinga and Bourdieu, even less so. Furthermore, to understand the transformation of play in modern, professional sport, the AFL can be used as a case study. The analysis of that league highlights the merger of the media field with the sport field (the AFL) and explores the impact this has had on the AFL and in particular, its play element. The analysis is supported by the views of the league's fans who shared their thoughts and views about the role of the media and the play element in the AFL during semi structured interviews as part of a broader PhD study on play and community.

\section{The Media and the AFL}

As part of a broader PhD study on the importance of play in stimulating community, fourteen AFL members, aged between twenty one and sixty, were interviewed about their observations of how the AFL had transformed since they had begun following the league. One of the main areas of discussion in the semi structured interviews was the media's influence in the sport. The responses are used to enrich the theory as 
they provide insight into how the changing structures and actions within the AFL, and its impact on the play element, have been observed in practice by members of the AFL's community.

As discussed, one of the most significant influences on the commodification of play is the media. For the media, play in the AFL is a vital commodity, a form of entertainment that produces huge audiences in return for substantial advertising revenues. According to Effie Caloutas, North Melbourne supporter, the media "expose the game to the public through advertising" and thus "increases participation through the grassroots and enhances its popularity" (personal communication 2015). For the AFL, the media offer invaluable assistance in selling its product and attracting the market to its brand. The AFL uses the popularity of the game to negotiate record amounts of money from the media for exclusive rights to broadcast play. Once they have purchased these rights, the media package the game as entertainment to enhance ratings and effectively sell audiences to advertisers. The higher the ratings, the larger the demand for advertising and, subsequently, the generation of greater revenue. In 2015, for example, the Seven Network earned an estimated $\$ 1.5$ million for every 5 minutes of advertising during the AFL Grand Final, with one 30-second national advertisement costing up to $\$ 150,000$ (Hayes, 2015). Thus, both media and league manage and manipulate play to make money.

Media interest in the AFL is almost like that of no other industry (sport or otherwise) in the world. The AFL and its clubs are broadcast to every corner of the nation by an unquenchably thirsty media insisting on covering the game - both on and off field - 365 days a year, 7 days a week, 24 hours a day. Several Essendon supporters reflected on this coverage. Michael Westland portrayed the changes from a historical perspective: "I remember football growing up as [being] Friday night, Saturday night, Sunday . . But these days footy is all encompassing" (personal communication 2013). Stuart Osbourne felt media influence had superseded the interests of football fans in the sheer number of matches scheduled for broadcast across a range of timeslots designed to maximise exposure of the AFL brand and increase ratings: "There are too many bloody time slots ... it's frigging impossible to plan your weekend when you go to the footy ... and it's all driven by broadcasters because they want every game live" (personal communication 2013). For Zak Kardachi, such coverage has led to "sensationalism", given that actual games occur on only two or three days of the week: "What do you write about as a news outlet when ... you have to fill seven days-worth of news" (personal communication 2013). Thus, he believed media have elected to provide "a lot of off-field talk that perhaps wasn't there before". Yet Westland noted many people, like himself, "surround" themselves with such coverage. They "find it informat[ive] and entertaining", relying not only on television, newspapers, and radio but also on newer technology to provide information.

For the media, the AFL sells, regardless of the time of year. Newspapers provide daily coverage and, during the season, add supplements dedicated to AFL-related stories. Radio stations incorporate AFL games as an integral part of their scheduling, with many offering magazine-style sports programs often broadcast during high-rating drive-time slots, to attract as many listeners as possible. The content of these shows primarily concerns the on-field performances of AFL players and teams and the off-field lives and issues of AFL players, personalities, and clubs. Radio has also introduced stations devoted solely to sports to target sports enthusiasts, employing former AFL players and current AFL commentators as hosts. Jeremiah Ryan, a Collingwood member, stated he takes advantage of the increased analysis provided in these programs and the convenience afforded from the multiple media formats used to broadcast games and related information: "I've got the AFL app on my iPad and I use that for scores when I'm at work or when I'm travelling . . . and I can watch a replay of Collingwood when I'm at work if I missed it" (personal communication 2013).

However, television has had the greatest impact on play in the AFL. Initially seen as a way of enabling all Australians to enjoy one of the nation's most enduring pastimes, television has elevated the emphasis on packaging and marketing the game to provide advertisers with increasing audience numbers. Game telecasts have become more and more aesthetically pleasing since the introduction of colour broadcasts in 1975, resulting in even higher levels of popularity. The media have added devices such as background music, emotive colour pieces, close-up shots of players and crowds, pre-taped and live interviews presented during matches, slow motion replays, graphics, symbols, and statistics (Goldlust 1987). 
Even commentators, once describers of what occurred on the field, have become entertainers and promoters of the AFL brand. They are to entertain their audiences to keep them watching and listening to keep their ratings high. Making negative comments about the league or a team, its coaches, or players is considered "trashing the AFL's brand", something the Sydney Swans and the AFL accused two Network Ten commentators of doing in 2006 (Wilson 2006a, 2006b). According to Tim Watson, Seven Network commentator, "You are employed by a radio broadcaster or a television network, so your responsibility is to your employer ... it is an entertainment and ... your responsibility is to provide entertainment" (personal communication, 2007). Rex Hunt, radio and television broadcaster for more than 40 years, concurred:

"When I am getting paid a serious amount of money to put the game into the houses of people, I

have a responsibility to entertain, because we are a commercial network . . we live and die by

the ratings, [so] we have to be entertaining to make sure people listen to us" (personal communication 2007).

Television media are among the biggest contributors to the AFL's overall revenue stream and, as such, one of the AFL's biggest stakeholders. In 2015, Seven Network and Foxtel paid a record $\$ 2.508$ billion to the AFL for broadcasting rights to all AFL preseason, home, away, and finals series games (McLachlan 2015). In 2016, despite increasing revenues by $\$ 11$ million, the AFL posted an overall loss of $\$ 17.8$ million. Its total operating expenditure increased to $\$ 18.8$ million, largely due to establishing the new AFL Women's competition and acquiring Etihad Stadium. Only seven of its clubs recorded a profit. However, despite relatively small net profits compared to other professional sporting organizations, the AFL puts most of its revenue back into the game, highlighting the importance of television broadcasting rights.

The media do not restrict their marketing efforts to advertising through television, radio, newspaper, and online, digital, and social media. They view the AFL and its clubs and collateral as effective tools in helping corporate sponsors reach mass markets. Indeed, the AFL and its clubs all have major sponsors with which they partner. These organizations generally believe sponsoring a league, team, event, or player will increase awareness of their company brand, products, and services and, in turn, improve their image and reputation. These firms also believe they will reach new demographics or audiences. In return for their sponsorships, corporate organizations can also receive naming rights to the teams' grounds and placement of their logos on team uniforms. Companies even sponsor individual players to benefit from their success or popularity. According to Sleight (1989, p. 199), "Media coverage is often the most crucial single element within the reasons for a company entering into a sponsorship".

The need to increase brand consumption and generate more broadcast and advertising revenue has also led the AFL to expand into northern Australian markets. By placing the Greater Western Sydney Giants and the Gold Coast Suns in areas typically not supportive of Australian football, the league has created the potential to sell to millions of new consumers and to increase broadcast audiences. In contrast, the AFL has rejected Tasmania's request for a football club because of the lack of the potential for new consumers. The Tasmanians have been playing the game for over 150 years and have followed the league for nearly as long. For Kardachi, even though not "commercially as viable" as the other two expansion teams, he believes that "if the AFL really wanted to love the game ... and [have it be] viewed by the people who really want to see it . . they' d probably have a team in Tasmania" (personal communication 2013). However, the interests of the media and the desire for ever increasing revenues outweigh the desires of the Tasmanians for their own team to support.

According to Kate Withers, Geelong Cats club member, "Clubs and the AFL itself are now beholden to the demands of advertisers, sponsors and broadcast partners" (personal communication 2015). Indeed, to ensure the game remains an attractive form of entertainment, the AFL has often regulated and changed game rules. Changes such as deliberate out of bounds, deliberate rushed behind, time limits for lining up for goals, kicking out immediately after an opposition has scored a behind, reducing the number of players on the interchange bench, and introducing substitute players have all been implemented to add to the game's entertainment value (AFL.com.au 2017). According to Withers, because "the game itself wouldn't exist without investment from media outlets ... advertising needs have taken priority over the actual integrity and purity of the game itself". 
Thus, play has become a function of business in the AFL, a tool used to generate interest in its brand and subsequent consumption of it. It is a form of entertainment that effectively turns players into entertainers, employed by their clubs to display their talents in return for their wages, wages now rivalling those of any celebrity in the entertainment industry.

Instead of a semi-professional, leisure time pursuit, play is now a full-time, professional form of employment. Thus, 'The spirit of the professional is no longer the true play spirit . . For the professional, playing is no longer just play. It is also work" (Huizinga 1950, p. 204).

As a result, players have become commodities of their clubs, traded to acquire better players or to ensure clubs can meet salary cap requirements. In turn, player loyalty has often been replaced with the lure of money and desires for financial security and prosperity. Although not new to the sport, players choosing to jump from their original teams to other clubs for more money has become more common as evidenced by the defections of Nathan Brown, Chris Judd, Gary Ablett Junior, Tom Scully, Callan Ward, Brendon Goddard and Lance "Buddy" Franklin. AFL teams have also trialled recruiting popular players from other sports, such as Karmichael Hunt and Israel Folau from the National Rugby League, in the hopes of increasing audiences and market share. The AFL has even excluded expansion teams such as the Suns and Giants from salary cap provisions, at least initially, to help them recruit experienced or popular players to make their teams more attractive to potential audiences. Free agency provisions have also contributed to the reduction of player loyalty, allowing clubs to offer certain players on rival teams higher salaries to induce them to jump.

The media has also affected players' abilities to earn income from sources other than their teams. Increased game coverage and interviews, profiles, and appearances on sports shows have resulted in more exposure for players than ever. Such exposure increases the numbers of their fans and mass followers on all forms of social media. As Essendon supporter Jason Lee noted, "Footballers have now become celebrities, not sports people" (personal communication 2013). Because of their resulting recognition power both within and beyond the sport, the AFL utilises them to sell the league's brand to consumers; and companies external to the AFL hire them to market, advertise, and sell their products and services.

\section{Play: The Importance of Winning}

Underlying the changes and emphasis on money is the imperative to win. Being successful on the field has never been more important as most sporting organisations consider winning an essential ingredient in making profit. Winning makes a team more valuable - winning teams garner more fan support, more advertising and broadcast revenue, and more sponsorships.

From its creation in the 1850s, Australian football has always emphasised winning to some degree; and players have always taken great pride in playing to their optimum capabilities and in being better than their opponents. The very structure and rules of the game promote recognition of the best. Winning the Grand Final to become the Premiership Team is the often identified goal of players, clubs, and those who barrack for their teams: a common goal they all work toward together resulting from a shared, common passion. Likewise, individual players have always been recognised and rewarded for being the best. Each team bestows a Best and Fairest award on the player whose contribution helped the team win most often. The AFL bestows the Brownlow Medal to the player the umpires judge to be the fairest and best. Other individual honours include the Most Valuable Player (Player's Association), the Coaches Award, and selection to the All Australian Team, which is composed of the 22 best players of the season. Originally, such recognitions were primarily expressions of the respect and admiration those in the sport field held for these teams and individuals. Achieving success on the field with their teammates and celebrating with the coaches, supporters, and administrators who worked together with them was largely considered reward enough.

However, the influence of the media has elevated winning (and its by-product of being recognized as the best), linking it inextricably with money. It allows clubs to attract more supporters, more members, and more spectators. It also allows clubs to sell more club merchandise, attract more corporate sponsors, and collect more money from those sponsors. Furthermore, winning enables clubs to play more games during primetime television slots that attract larger audiences and, hence, more money. Tom Gallimore, Brisbane Lions 
supporter, remarked that clubs must "keep generating revenue and money to be a successful club" (personal communication 2013).

To keep winning, clubs spend money on attracting and developing the best coaches, the best equipment, and the best players. They cultivate extensive training and development programs to keep their teams winning and to ensure their brands remain attractive to all possible sources of revenue, including fans, club members, sponsors, media outlets, and broadcast audiences.

Winning also focuses attention on players who make it possible. Recognition for their individual accomplishments on the field earns them rewards and praise, including better compensation from their clubs. In turn, these individuals help sell club brands. Individual players are also more likely to garner lucrative contracts from corporate sponsors to promote company brands and products.

In contrast, off-field consequences for losing teams can be quite serious. Poor on-field performance diminishes the club's brand, which reduces its ability to earn money. Few corporate sponsors want to support losing teams. Although diehard fans may remain unwavering in their support, those not as dedicated or connected may choose not to renew their club memberships, to attend fewer games, or to buy less club merchandise. Losing teams also do not get many primetime broadcast slots, decreasing the amount of exposure generated from playing during television's most popular time. Less money means lessened abilities to recruit the best players and coaches, to provide the latest and best equipment, or to create and maintain player development programs.

Ultimately, winning is the reason the AFL pumps much of its profits back into the league and its teams. It is the reason for the Equalisation Policy, for exempting expansion teams from the provisions of that policy, the reason key players jump from one team to another and teams recruit players from other teams and other sports.

The importance of winning is clearly seen in the emphasis on coaching. Not only have the number of coaches increased but also their level of influence on how the game is played. Collingwood member, Jeremiah Ryan stated footy departments had grown from relatively small staffs (i.e., "a head coach, a forward line coach, mid field coach and a backline coach") to staffs in which assistant coaches have assistants, including "developing coaches and tactical analysts and guys that don't even see their own club play. All they do is watch the team their club is playing next week" (personal communication 2013).

What constitutes coaching has also changed. Lee explained coaches used to focus on the "fire and brimstone sort of stuff . . . [to] motivate players" (personal communication 2013). Today, the coach's role is "very strategic". Coaches rely on data, about their team and opposing teams, to inform their decisions concerning play. They analyse each player's performance and implement training programs designed to maximize individual and team capabilities. They design strategic game plans, prescribe game tactics, structure every second of on-field play, and expect players to implement those plans and tactics without question. Thus, coaches have become more influential in how games are played than the players on the field. As Osbourne reflected, "There's an environment for footy that's been created, I think, by the amount of money that's in the game now. . . the way the game has changed over the last ten years has been driven by coaches trying to get the best competitive advantage on the field" (personal communication 2013).

Interestingly, Ryan noted that although coaches have more influence, "the AFL's really been wrestling with the coaches to ... get it [play] to what the AFL wants it to look like" (personal communication 2013). He believed coaches just want to win. The AFL, however, is concerned about image. Scoring more goals means more excitement; more excitement makes the game more attractive to media, advertisers, and corporate sponsors. This is somewhat paradoxical because the coaches' manipulation of the game through team rules, player development regimens, data collection and analysis, and strategic game plans and tactics, has resulted in somewhat homogenous play in the league, each team's game plan and style mirroring that of every other team.

Thus, individual players are less likely to play with the flair, freedom, spontaneity, creativity, and enjoyment once evident in the game. Restricted to the overarching confines of the game plan, "All players in all teams play a role as part of the system of play that their coach wants them to play" (Stuart Osbourne, personal communication 2013). However, for Geelong supporter Scott Hutchins, although "team orientation 
is obviously important ... a player's individual flair and brilliance is always going to over shine the coaches' team structures and systems" (personal communication, 2013).

Winning is so important many clubs and players have adopted a win-at-all-costs attitude. In manipulating play to ensure victories, they often take drastic measures and increasingly push the boundary between what is fair and legal and what is not to gain an advantage over their opponents. This all-encompassing desire to win has led to more and more reliance on sports science to ensure players and their teams play at their maximum capabilities and sustain maximum output. Where players once relied on hard work and natural ability to win, today they are assisted by sports scientists who provide supplements and dietary advice to improve performance.

When legitimate sports science methodology fails to ensure winning, teams and players may resort to other means to achieve their goals, including the use of illegal substances to stoke players' abilities. Players who use or attempt to use illegal substances to enhance their performance are effectively guilty of cheating because such substances enable the body to perform above its natural capacity. Thus, athletes who take such substances eliminate the essence of fair play because they have attempted to give themselves unfair and unnatural advantages over their opponents.

In 2012, the Essendon Football Club asked the AFL and the Australian Sports Anti-Doping Agency (ASADA) to determine whether substances their players were administered in 2012 were legal (AFL.com, 2013a). The investigation centred on the use of Thymosin Beta 4. Although the interim report indicated the ASADA had not found evidence of substance abuse or cheating, the AFL charged four Essendon officials for bringing the game into disrepute. Senior Coach James Hird was subsequently banned from working at any AFL club for 12 months. Ultimately, in January 2016, 34 past and present Essendon players were found guilty of being administered Thymosin Beta 4 and were subsequently banned from playing during the 2016 season.

The use of illegal drugs, however, is not confined to team practices. The Australian Crime Commission (ACC 2012) found links between use of illegal substances and organised crime and match fixing, "present[ing] a threat to the integrity of Australian professional sport". The ACC noted criminals can corrupt athletes who buy and use these substances, coercing them into influencing the outcomes of their matches to ensure individuals gambling on these events win. Among other things, such athletes may be asked to manipulate games by ensuring their teams do not win, minimizing the number of goals scored, or providing insider information. Although no examples of match fixing have been found within the AFL, the potential is quite real as evidenced by occurrences in other sports and the disciplining of two Collingwood players, Heath Shaw and Nick Maxwell, for violating AFL anti-gambling regulations.

Another practice teams may employ to increase their chances of winning is tanking. Tanking requires management, coaches, and/or players to manipulate play during a match to achieve a contrived result. Until 2012, under the Equalisation Policy, a team that won no more than 4 out of the 22 matches played during the season received an extra draft pick. Thus, teams who believed they needed a significant boost of the best young talent available in the next National Draft might resort to losing deliberately.

The AFL investigated the 2009 season of the Melbourne Club to determine whether tanking had, indeed, occurred after a former player, Brock McLean, who played for Melbourne during the 2009 season, stated on national television the team had deliberately lost some of its games (Fox Footy 2012). The investigation revealed no evidence the team had done anything other than their best on match days. However, it did reveal that General Manager of Football Operations Chris Connolly and Senior Coach Dean Bailey had made comments and acted in ways prejudicial to the AFL by preparing the team to lose and selecting teams that would probably not win. Both men were subsequently disciplined by the league. Because the club was ultimately responsible for the actions of its employees, the AFL also fined Melbourne $\$ 500,000$. The AFL then changed its priority selection procedures to make it harder for teams to qualify (AFL.com 2013b).

Tanking stands in opposition to the heritage of Australian football of members, supporters, administrators, coaches, and players working together to achieve the common, shared goal of trying one's best to win the premiership. Yet fans seem split on the issue. Hawthorn supporter Josh Forte felt 'it would be remiss of a club not to tank ... with the prizes on offer for failing' (personal communication 2013). Carlton member 
Alanna Ford stated she would "rather be proud of a team that plays with integrity and honesty and loses ... than one who may/may not improve because they have tanked for draft picks" (personal communication 2015). Cheree Brown, a Sydney Swans supporter, and Caloutas concurred (personal communications 2015). For Gallimore, tanking is "un-Australian" and he "would feel a little gutted" if he learned his team had used tanking as "a deliberate tactic" (personal communication 2013). Kardachi was even more forceful: "It's the same as stealing ... You subverted the rule, you took advantage of the rules, and you did something that is not in the spirit of the game ... to possibly secure a future" (personal communication 2013).

\section{Conclusion}

It is clear the combined theories of Huizinga and Bourdieu provide a theoretical framework that can be applied to sport, and in particular, the AFL, as a means of understanding the influence of the media field in transforming the play element and in highlighting the link between play, as a function of business, and making money. While Huizinga would bemoan play's transformation as "corruption", it appears irreversible in professional sport, as outlined through the case study of the AFL. Play is no longer a completely creative, spontaneous "discharge of super abundant vital energy." It is now managed for business and commercial outcomes. Developing an attractive brand is aligned with winning, thus play is managed and analysed to win, or not to lose. The result of play matters more than ever in the commercial environment of professional sport and the consequences of a match's outcome stretch well beyond the play contest.

Indeed, the relationship between the media and the AFL is symbiotic. The media need the ever-growing popularity of the AFL to sell advertising; the league needs the media for its broadcasting rights revenue and to help promote and grow the game across the country. Thus, money rather than the game has become the most prominent feature of play in the AFL, with the media, fuelled by economics, commodifying play from the creative, spontaneous element it once was into a function of business.

Nothing underscores that function better than the elevated importance in the AFL of winning. Winning teams gain recognition from the public, media and advertisers. More recognition means increased revenues not only from ticket sales, club memberships, and brand merchandise, but also from corporate sponsorships. Increased revenues allow teams to invest in premium players and coaches, the highest quality training programs, and sports science to propel their players to their maximum capabilities to keep winning. However, the imperative to win has also resulted in the management and potential manipulation of play by coaches, players, administrators, and teams.

Fans are keenly aware of the transformation of the AFL from game to sport, to business and the resulting impact of the media on play. As Phil Wild stated, "eyeballs mean dollars . . it's a pretty simple business equation" (personal communication, 2013). They understand the media are the biggest contributors of revenue to the AFL and, thus, the most powerful stakeholders. As such, they understand the media have the biggest say in the direction of the AFL and the decisions made in furthering that direction. For fans, that can be a sobering realisation. As Wild stated, "While generally what the media want and what the fans want would hopefully be sort of congruent ... when push comes to shove" the desires of the media will win out over those of the fans.

\section{REFERENCES}

AFL.com.au. (2017). AFL rules-Laws of the game 2017 (2017). Retrieved July 13, 2017, from http://www.afl.com.au/afl-hq/laws-of-the-game

AFL.com.au, (2013a). Full statement from Essendon chairman David Evans. Retrieved February 27, 2013, from http://www.afl.com.au/news/2013-02-27/full-statement-from-essendon

AFL.com.au (2013b). A full statement: Melbourne tanking penalties. Retrieved March 28, 2013, from http://www.afl.com.au/news/2013-02-19/afl-full-statement-melbourne-tanking-penalties

Australian Crime Commission. (2013, February). Organised crime and drugs in sport: New generation performance and image enhancing drugs and organised crime involvement in their use in professional sport. Retrieved March 2, 2014 from https://www.crimecommission.gov.au/sites/default/files/organised-crime-and-drugs-in-sport-feb2013.pdf

Bourdieu, P. (1986). The Forms of Capital. In J.G. Richardson (Ed.), Handbook of Theory and Research for the Sociology of Education (pp. 241-258). New York: Greenwood Press.

Bourdieu, P. (1979). Outline of a Theory of Practice. Cambridge: Cambridge University Press. 
Bourdieu, P. (1993). Sociology in Question trans. Richard Nice, London: Sage.

Bourdieu, P. (1990). Structures, Habitus, Practices. In P. Bourdieu (Ed.), The Logic of Practice. Stanford, Stanford University Press.

Caillois, R. (2006). The Definition of Play and The Classification of Games. In K. Salen, and E. Zimmerman (Eds.), The Game Design Reader: A Rules of Play Anthology, Massachusetts. Boston: Institute of Technology.

Duncan, S. (2016). Footy Grounds to Grandstands: Play, Community and the Australian Football League. Port Adelaide: Ginninderra Press.

Fox Footy. (2012). On the couch: Interview with Brock Mclean. (2012, July 30). Melbourne: Fox Sports.

Goldlust, J. (1987). Playing for Keeps: Sport, the Media and Society. Melbourne: Longman Cheshire.

Hans, J.S. (1981). The play of the world. Boston: University of Massachusetts Press.

Hayes, A. (2015). How much does it cost to get an NRL and AFL grand final TV advertising spot? Retrieved July 13, 2017, from https://mumbrella.com.au/how-much-does-it-cost-to-get-an-nrl-and-afl-grand-final-tv-advertising-spot$\underline{322414}$

Huizinga, J. (1950). Homo Ludens: A Study of the Play-Element in Culture. Boston: Beacon Press. First published in 1938 by Wolters-Noordhoff.

Lasch, C. (1980). The Culture of Narcissism: American Life in an Age of Diminishing Expectations. London: Abacus.

Millar, S. (1968). The psychology of play. Oxford: Penguin Books Ltd.

McLachlan, G. (2015). AFL CEO Gillon McLachlan's statement on new broadcast deal. Retrieved August 18, 2015, from http://www.afl.com.au/news/2015-08-18/afl-ceo-gillon-mclachlans-statement-on-new-broadcast-deal

Nicholson, M., Kerr, A. \& Sherwood, M. (2015). Sport and the Media: Managing the Nexus. $2^{\text {nd }}$ edn. London: Routledge.

Orive, S. (1996). Victorian Rules: Populi Ludos Populo-The Game of the People for the People. Melbourne: State Library of Victoria.

Rowe, D. (2004). Understanding sport and media: A socio-historical approach. In: Sport, Culture and the Media: The Unruly Trinity 2nd edn. (pp. 11-36). Berkshire: Open University Press.

Sutton-Smith, B. (1997) The ambiguity of play. Cambridge: Harvard University Press.

Sleight, S. (1989). Sponsorship: What It Is and How to Use It. Berkshire: McGraw-Hill.

Tomlinson, A. (2004). Pierre Bourdieu and the Sociological Study of Sport: Habitus, Capital and Field. In R. Guilianotti (Ed.), Sport and Modern Social Theorists. Basingstoke: Palgrave Macmillan.

Wilson, C. (2006a, August 11). Fair call? No way say clubs' chief executives. Retrieved April 27, 2013, from http://www.theage.com.au/afl//news/afl/fair-call-no-way-say-club-executives/200608/10/1154803032324.html

Wilson, C. (2006b). Roos fuming at ten's commentary. (2006, August 15). The Age, p. 89.

AUTHOR'S ADDRESS: $\quad$ Samuel Keith Duncan

Holmesglen Institute

4/22 Tintern Avenue, Toorak, Victoria

Australia, 3142

E-mail: Sam.Duncan@holmesglen.edu.au

Received: 15 January 2018; Accepted: 28 Febraury 2018 